\title{
Surgical drainage after limb salvage surgery and endoprosthetic reconstruction: is 30 $\mathrm{mL} /$ day critical?
}

Jiayong Liu' ${ }^{1 \dagger}$, Zhengfu Fan ${ }^{1 \dagger}$, Marc El Beaino ${ }^{3,2}$ (D), Valerae O. Lewis ${ }^{3}$, Bryan S. Moon ${ }^{3}$, Robert L. Satcher ${ }^{3}$, Justin E. Bird ${ }^{3}$, Spencer J. Frink ${ }^{3}$ and Patrick P. Lin ${ }^{3^{*}}$ (I)

\begin{abstract}
Background: Periprosthetic infection is a major cause of failure after segmental endoprosthetic reconstruction. The purpose of this study is to determine whether certain aspects of drain output affect infection risk, particularly the $30 \mathrm{~mL} /$ day criterion for removal.

Methods: Two hundred and ninety-five patients underwent segmental bone resection and lower limb endoprosthetic reconstruction at one institution. Data on surgical drain management and occurrence of infection were obtained from a retrospective review of patients' charts and radiographs. Univariate and multivariate Cox regression analyses were performed to identify factors associated with infection.

Results: Thirty-one of 295 patients (10.5\%) developed infection at a median time of 13 months (range 1108 months). Staphylococcus aureus was the most common organism and was responsible for the majority of cases developing within 1 year of surgery. Mean output at the time of drain removal was $72 \mathrm{~mL} /$ day. Ten of 88 patients (11.3\%) with $\leq 30 \mathrm{~mL} /$ day drainage and 21 of 207 patients (10.1\%) with $>30 \mathrm{~mL} /$ day drainage developed infection $(p=0.84)$. In multivariate analysis, independent predictive factors for infection included sarcoma diagnosis (HR 4.13,95\% Cl 1.4-12.2, $p=0.01$ ) and preoperative chemotherapy (HR 3.29, $95 \% \mathrm{Cl} 1.1-9.6, p=0.03)$.

Conclusion: Waiting until drain output is $<30 \mathrm{~mL} /$ day before drain removal is not associated with decreased risk of infection for segmental endoprostheses of the lower limb after tumor resection. Sarcoma diagnosis and preoperative chemotherapy were independent predictors of infection.
\end{abstract}

Keywords: Periprosthetic infection, Surgical drain, Sarcoma, Bone resection

\footnotetext{
* Correspondence: plin@mdanderson.org

${ }^{\dagger}$ Jiayong Liu and Zhengfu Fan contributed equally to this work.

${ }^{3}$ Department of Orthopedic Oncology, MD Anderson Cancer Center, Houston, TX, USA

Full list of author information is available at the end of the article
}

(c) The Author(s). 2021 Open Access This article is licensed under a Creative Commons Attribution 4.0 International License, which permits use, sharing, adaptation, distribution and reproduction in any medium or format, as long as you give appropriate credit to the original author(s) and the source, provide a link to the Creative Commons licence, and indicate if changes were made. The images or other third party material in this article are included in the article's Creative Commons licence, unless indicated otherwise in a credit line to the material. If material is not included in the article's Creative Commons licence and your intended use is not permitted by statutory regulation or exceeds the permitted use, you will need to obtain permission directly from the copyright holder. To view a copy of this licence, visit http://creativecommons.org/licenses/by/4.0/ The Creative Commons Public Domain Dedication waiver (http://creativecommons.org/publicdomain/zero/1.0/) applies to the data made available in this article, unless otherwise stated in a credit line to the data. 


\section{Background}

Periprosthetic infection is a potentially devastating complication for oncologic patients undergoing segmental bone resection and endoprosthetic reconstruction. Even after multiple operations and extended courses of antibiotics, infection can ultimately be the cause for loss of limb rather than the original neoplasm. With an incidence of approximately $10 \%$ for large segmental prostheses, periprosthetic infection represents a major mode of failure [1-3].

There are many serious consequences of infection $[4,5]$. Hospitalization may be prolonged, and the cost of treatment can be substantial [6, 7]. Function can be compromised as a result of joint stiffness, increased pain, and, for some patients, amputation [8-11]. A delay in resumption of adjuvant chemotherapy for sarcomas could jeopardize survival [12].

The surgical drain poses a potential risk for infection because it can create a conduit to the skin and become colonized with bacteria [4]. Persistent postoperative drainage beyond $48 \mathrm{~h}$ has been reported to be a risk factor for infection after conventional arthroplasty [4, 13-15]. Postoperative drainage is greater in patients undergoing segmental endoprosthetic reconstruction than those undergoing primary joint arthroplasty since a much larger volume of tissue must be removed. This may be one reason why the rate of periprosthetic infection is higher after modular segmental endoprosthetic reconstruction compared to conventional arthroplasty [8]. However, there is little data to guide surgeons in the management of surgical drains after tumor resection. It is still unknown whether multiple drains are beneficial, how long drains can be left in place safely, and what volume of drainage is permissible for drain removal. A commonly used cutoff of $30 \mathrm{~mL} /$ day is used for discontinuation of drains in the USA [16, 17], but the threshold for drain removal is not well-defined or studied in the orthopedic oncology literature.

The present study was undertaken to determine whether certain aspects of surgical drain management might be related to infection for oncologic patients undergoing segmental bone resection. In particular, we were interested to know whether waiting until the rate of drain output was $\leq 30 \mathrm{~mL} /$ day before drain removal reduced the risk of infection. The study represents the largest cohort reported to date examining specifically the relationship of surgical drainage to periprosthetic infection in patients with modular endoprostheses.

\section{Methods}

\section{Study design}

A retrospective observational study with univariate and multivariate analysis was performed on a consecutive series of patients treated at one hospital meeting eligibility requirements. The primary endpoint was to identify predictive factors for periprosthetic infection. For the purposes of this study, the diagnosis of periprosthetic joint infection required a positive microbiologic culture from the joint fluid, surgical site, or wound. The diagnosis of infection was confirmed by supporting evidence from the patient's history, physical examination, blood tests, and radiographs [18]. All cases of periprosthetic infection, no matter how late they occurred, were included in the analysis for risk factors. The study was performed with approval by the Institutional Review Board.

\section{Study population}

The Orthopaedic Oncology Surgical Database at a single institution was queried for segmental bone resection and primary (non-revision) lower limb endoprosthetic reconstruction between 2000 and 2012. Minimum follow-up was 12 months unless patients died prior to 12 months. Out of 314 candidate cases, 19 (6\%) were excluded for lack of follow-up and missing data. The remaining 295 patients formed the cohort for the present study. Demographic characteristics are listed in Table 1. The median follow-up was 36 months. Kaplan-Meier overall survival at 5 years for the study cohort was $52 \%$ (Fig. 1). There were 160 (54\%) males and 135 (46\%) females. The mean age was 41 years (range 6-84 years). Surgical sites were limited to proximal femur, distal femur, proximal tibia, and total femur. Disease categories included 14 (5\%) benign tumors, 86 (29\%) metastatic tumors (carcinomas and multiple myeloma), and 195 (66\%) sarcomas.

\section{Surgery and drain management}

All patients had intravenous antibiotics administered immediately prior to skin incision. Patients received cefazolin for preoperative surgical prophylaxis unless patients had penicillin or cephalosporin allergy, in which case clindamycin was employed. For prolonged cases, the antibiotics were re-dosed after $6 \mathrm{~h}$. There was no prospective protocol for drain management with regard to number of drains or duration of drains. The following information about postoperative drainage was collected from the patient files: number of drains, duration of drains, daily drain output, total drain output, mean output per day, and drain output on the last day (over $24 \mathrm{~h}$ ).

\section{Statistics}

Descriptive statistics were calculated and reported in terms of means, medians, and proportions. Bivariate linear regression was performed to assess the potential relationship of various continuous variables. Pearson's correlation coefficient $R$ was calculated for each pair of variables, and scatter plots with linear regression lines 
Table 1 Demographic characteristics

\begin{tabular}{|c|c|c|c|c|}
\hline Characteristic & Group & Value & $N$ & $\%$ \\
\hline Total patients & & & 295 & \\
\hline \multirow[t]{2}{*}{ Periprosthetic infection } & Yes & & 31 & 11 \\
\hline & No & & 264 & 89 \\
\hline \multirow[t]{2}{*}{ Follow-up (months) } & Median & 36 & & \\
\hline & Range & $1-201$ & & \\
\hline \multirow[t]{2}{*}{ Vital status } & Alive & & 131 & 44 \\
\hline & Dead & & 164 & 56 \\
\hline \multirow[t]{2}{*}{ Gender } & Male & & 160 & 54 \\
\hline & Female & & 135 & 46 \\
\hline \multirow[t]{3}{*}{ Age (years) } & Mean & 41 & & \\
\hline & Median & 42 & & \\
\hline & Range & $6-84$ & & \\
\hline \multirow[t]{7}{*}{ Diagnosis } & Osteosarcoma & & 127 & 43 \\
\hline & Chondrosarcoma & & 30 & 10 \\
\hline & Ewing sarcoma & & 11 & 4 \\
\hline & Other sarcoma & & 27 & 9 \\
\hline & Giant cell tumor & & 14 & 5 \\
\hline & Renal cell carcinoma & & 31 & 11 \\
\hline & Other metastasic carcinomas and multiple myeloma & & 55 & 19 \\
\hline \multirow[t]{4}{*}{ Site } & Proximal femur & & 97 & 33 \\
\hline & Distal femur & & 131 & 44 \\
\hline & Total femur & & 13 & 4 \\
\hline & Proximal tibia & & 54 & 18 \\
\hline \multirow[t]{5}{*}{ Chemotherapy } & Preoperative & & 186 & 63 \\
\hline & Postoperative & & 173 & 59 \\
\hline & Any (pre- or post-) & & 206 & 70 \\
\hline & Both (pre- and post-) & & 152 & 52 \\
\hline & None & & 89 & 30 \\
\hline \multirow[t]{3}{*}{ Radiation } & Preoperative & & 38 & 13 \\
\hline & Postoperative & & 26 & 9 \\
\hline & None & & 231 & 78 \\
\hline \multirow[t]{3}{*}{ Resection length (cm) } & Mean & 17 & & \\
\hline & Median & 16 & & \\
\hline & Range & $4-53$ & & \\
\hline \multirow[t]{4}{*}{ Surgical drains } & 1 & & 194 & 66 \\
\hline & 2 & & 90 & 31 \\
\hline & 3 & & 10 & 3 \\
\hline & 4 & & 1 & 0 \\
\hline \multirow[t]{3}{*}{ Total drainage $(\mathrm{L})$} & Mean & 1.4 & & \\
\hline & Median & 1.1 & & \\
\hline & Range & $0.1-22.4$ & & \\
\hline \multirow[t]{3}{*}{ Time of drainage (days) } & Mean & 8 & & \\
\hline & Median & 7 & & \\
\hline & Range & $1-48$ & & \\
\hline
\end{tabular}


Table 1 Demographic characteristics (Continued)

\begin{tabular}{llll}
\hline Characteristic & Group & Value & N \\
\hline${\text { Average daily drainage }{ }^{\text {a }}(\mathrm{mL} / \text { day })}$ & Mean & 170 \\
& Median & 157 \\
Last day of drainage $(\mathrm{mL})$ & Range & $3-655$ \\
& Mean & 72 \\
Operative time (hours) & Median & 60 \\
& Range & $0-510$ \\
Estimated blood loss $(\mathrm{mL})$ & Mean & 5.3 \\
& Median & 5.0 \\
& Range & $1.7-14.7$ \\
\hline
\end{tabular}

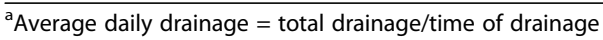

Abbreviations: $L$ liter

were generated by least squares. Univariate analysis for association with periprosthetic infection was performed for both categorical and continuous variables. The chisquare and Fisher's exact tests were used to assess categorical variables in $2 \times 2$ comparisons. The means of continuous variables were compared with Student's $t$ test. The drain output on the last day was also analyzed as categorical variables by three different groupings with cut-off values at 30, 60, and $120 \mathrm{~mL} /$ day. Of note, $60 \mathrm{~mL} /$ day corresponded to the median drain output on the last day of the drain. The $120 \mathrm{~mL} /$ day value was intended to be a high value above median to test whether infections clustered in patients with very high output on the last day of the drain.

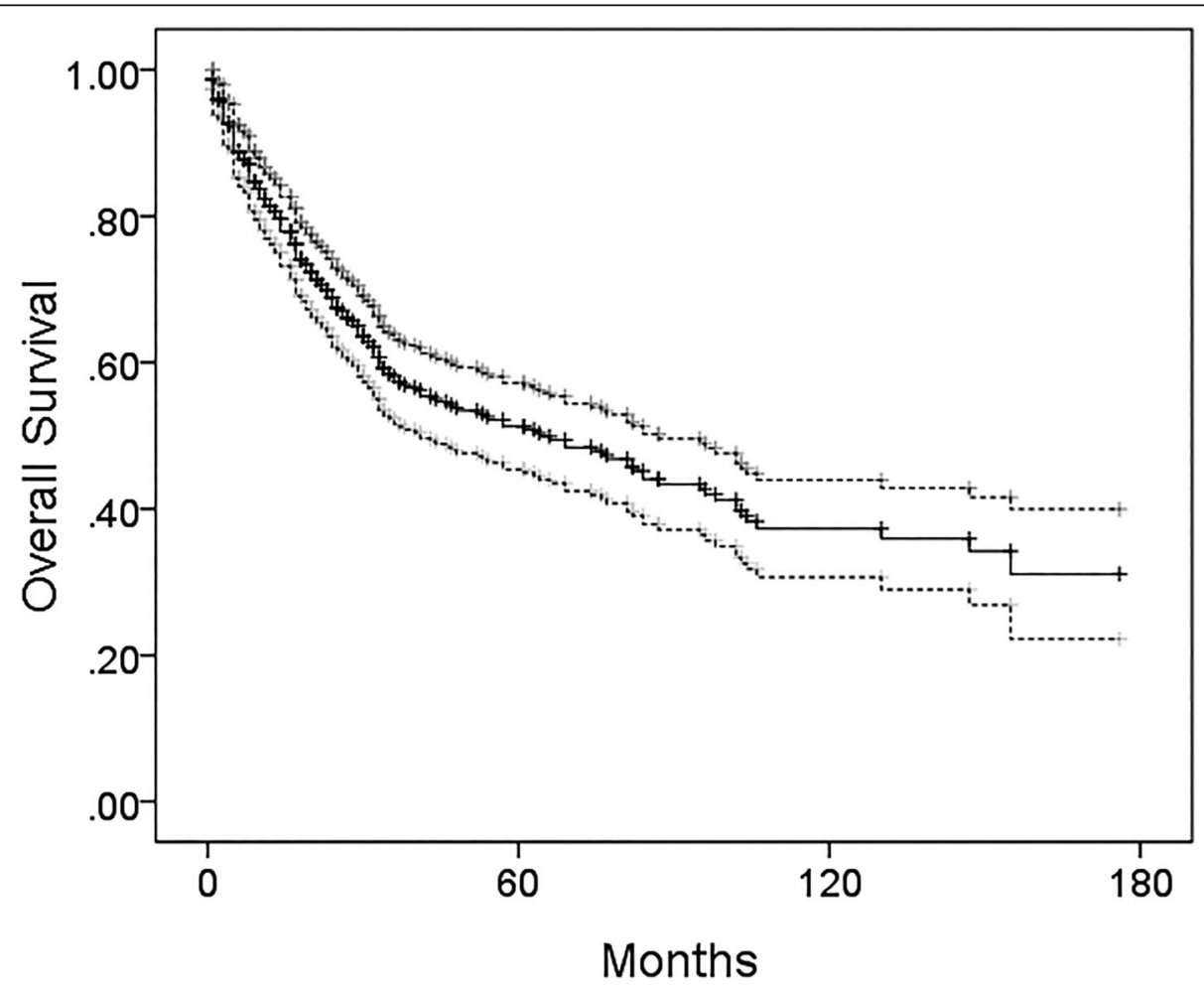

Fig. 1 Overall survival. For the entire cohort of 295 patients, the overall survival was 52\% at 5 years and 38\% at 10 years by Kaplan-Meier survivorship analysis. The $95 \%$ confidence interval for overall survival is shown 
Variables with $p<.10$ in univariate analysis were entered in multivariate Cox regression analysis for periprosthetic infection to identify independent risk factors. A forward conditional methodology based on likelihood ratio was used for entry of variables into the model. A $p$ value < 0.05 was considered to be statistically significant. All analyses were performed with $\mathrm{SPSS}^{\bullet}$ version 24.0 for Windows (IBM Corp., Armonk, NY).

\section{Results}

\section{Infection rate and pathologic organisms}

Thirty-one of 295 cases (10.5\%) developed periprosthetic infection at a median time of 13 months (range 1-108 months). Fifteen patients developed infection within a year of surgery; 11 patients developed infection between 1 and 5 years after surgery, and 5 patients developed infection after 5 years from surgery. The most common organisms isolated were Staphylococcus aureus $(n=12$, of which 9 were methicillin-resistant), other Staphylococcus species $(n=6)$, Streptococcus species $(n=3)$, Enterobacteriaceae species $(n=3)$, and Candida species $(n=$ 3). Rare organisms (one each) included Propionibacterium acnes, Enterococcus, Stomatococcus, Corynebacterium, Prevotella, Fusobacterium, and other anaerobic organisms (Table 2). Three patients had polymicrobial infections. Infections due to Staphylococcus aureus clustered in cases with acute onset within 1 year of surgery (Table 2).

\section{Surgical drain output}

The mean total amount of drain output was 1.4 L (range 0.1-22.4 L, standard deviation 1.6 L). Factors that correlated positively with total drain output included time of drainage $(R=0.79, p<0.001$, Fig. 2$)$, mean drain output ( $R=0.50, p<0.001)$, volume of drainage on the last day $(R=0.47, p<0.001)$, number of drains $(R=0.19, p=$ $0.001)$, resection length $(R=0.019, p=0.001$, Fig. 3$)$, and age $(R=0.16, p=0.007)$.

\section{Univariate analysis for periprosthetic infection}

Individual factors were analyzed in univariate analyses for possible association with periprosthetic infection (Table 3). Of the non-drain-related variables, patients who had male gender, younger age, preoperative chemotherapy, postoperative chemotherapy, both pre- and postoperative chemotherapy, and sarcoma diagnosis were more likely to develop infection. Both the length of surgery and the need for re-dosing antibiotics during the surgery were associated with a greater rate of infection. Factors not associated with infection included length of resection, site of disease, preoperative radiation, postoperative radiation, and surgeon.

Table 2 Pathogenic isolates and onset of infection

\begin{tabular}{|c|c|c|c|}
\hline \multirow[t]{2}{*}{ Organism } & \multicolumn{3}{|l|}{$\begin{array}{l}\text { Onset of Infection } \\
\text { (Number of cases) }\end{array}$} \\
\hline & $\begin{array}{l}<1 \text { year } \\
\text { (number of cases) }\end{array}$ & $\begin{array}{l}1-5 \text { years } \\
\text { (number of cases) }\end{array}$ & $\begin{array}{l}>5 \text { years } \\
\text { (number of cases) }\end{array}$ \\
\hline Staphylococcus aureus, methicillin-resistant & 6 & 2 & 1 \\
\hline Staphylococcus aureus, methicillin sensitive & 3 & & \\
\hline Staphylococcus, coagulase negative & 2 & 1 & \\
\hline Staphylococcus epidermidis & & 1 & 1 \\
\hline Staphylococcus warneri & & & 1 \\
\hline Streptococcus, Group B & 1 & 1 & \\
\hline Streptococcus, Group G & & 1 & \\
\hline Candida species & 1 & 1 & 1 \\
\hline Enterococcus & 1 & & \\
\hline Stomatococcus & & 1 & \\
\hline Enterobacter & 1 & & \\
\hline Enterobacteriaceae species & & 2 & \\
\hline Propionibacterium acnes & & & 1 \\
\hline Lactobacillus & & 1 & \\
\hline Corynebacterium & & & 1 \\
\hline Gram variable rod (not otherwise specified) & & 1 & \\
\hline Fusobacterium & & 1 & \\
\hline Prevotella corporis & & 1 & \\
\hline
\end{tabular}




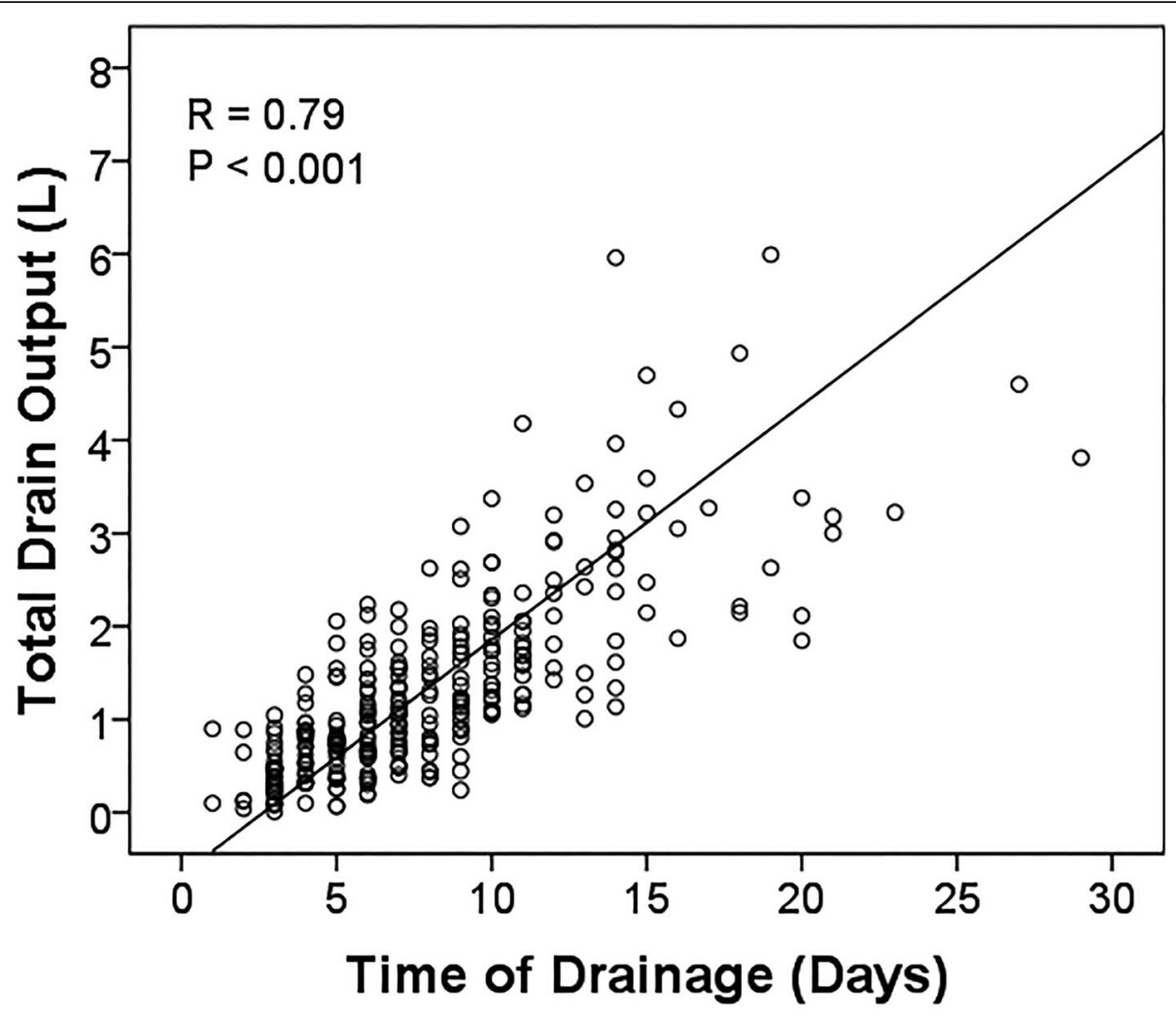

Fig. 2 Drain output and duration of drains. Linear regression was performed to analyze the potential relationship between total drain output and duration of drains. A scatterplot with best-fit line is shown for total drain output ( $L$, liters) and duration of surgical drains (Pearson's correlation coefficient $R=0.79, p<0.001$ )

Of the drain-related variables, factors associated with infection included total volume of drainage, multiple (> 1) drains, days of drainage, and mean rate of drainage per day (Table 3). The amount of drainage on the last day did not predict infection (Table 3 ). The mean drainage on the last day was $70 \mathrm{~mL} /$ day for uninfected cases and $73 \mathrm{~mL} /$ day for infected cases $(p=0.94)$. Using the median rate of drainage on the last day $(60 \mathrm{~mL}$ per day) as a cut-off value for grouping, 14 of 152 patients (9.2\%) who had less than the median developed infections whereas 17 of 143 patients $(11.9 \%)$ with greater than the median had infections $(p=0.57)$. Using the cut-off of 30 $\mathrm{mL}$ per day on the last day of the drain, patients who had less than $30 \mathrm{~mL} /$ day did not have significantly fewer infections than patients who had greater than $30 \mathrm{~mL} /$ day (Table 3). Similarly, using a cut-off value of $120 \mathrm{~mL} /$ day did not reveal a significant association with infection (Table 3).

\section{Multivariate analysis}

The following factors with a $\mathrm{p}$ value $<0.10$ in univariate analysis were entered into a multivariate Cox regression analysis to identify independent covariates of infection: gender, resection length, preoperative chemotherapy, postoperative chemotherapy, any chemotherapy, both pre- and postoperative chemotherapy, number of drains, drain duration, rate of drainage, total volume of output, operative time, estimated blood loss, re-dosing of antibiotics, and sarcoma diagnosis. The independent factors in the final equation included sarcoma diagnosis (HR 4.13, 95\% CI 1.4-12.2, $p=0.01$ ) and preoperative chemotherapy (HR 3.29, 95\% CI 1.1-9.6, $p=0.03$ ) (Table 4). Male diagnosis did not reach statistical significance (HR 2.5, 95\% CI 0.9-6.8, $p=0.08$ )

\section{Discussion}

Infection is a major cause of failure after segmental bony resection and modular endoprosthetic reconstruction. The rate of periprosthetic infection in this study was $10.5 \%$, which is similar to the rate reported in other articles for modular endoprostheses [1, 19]. The risk factors for infection can be broadly placed into two main categories: patient-related and treatment-related variables [20-22]. The surgical drain is a treatment-related risk factor, but it has not received much attention in the literature pertaining to segmental endoprostheses. Previous studies have examined the relationship between infection and drainage in conventional arthroplasty [13, 23]. Prolonged duration of an indwelling surgical drain increases the likelihood of infection [13, 24]. Each 


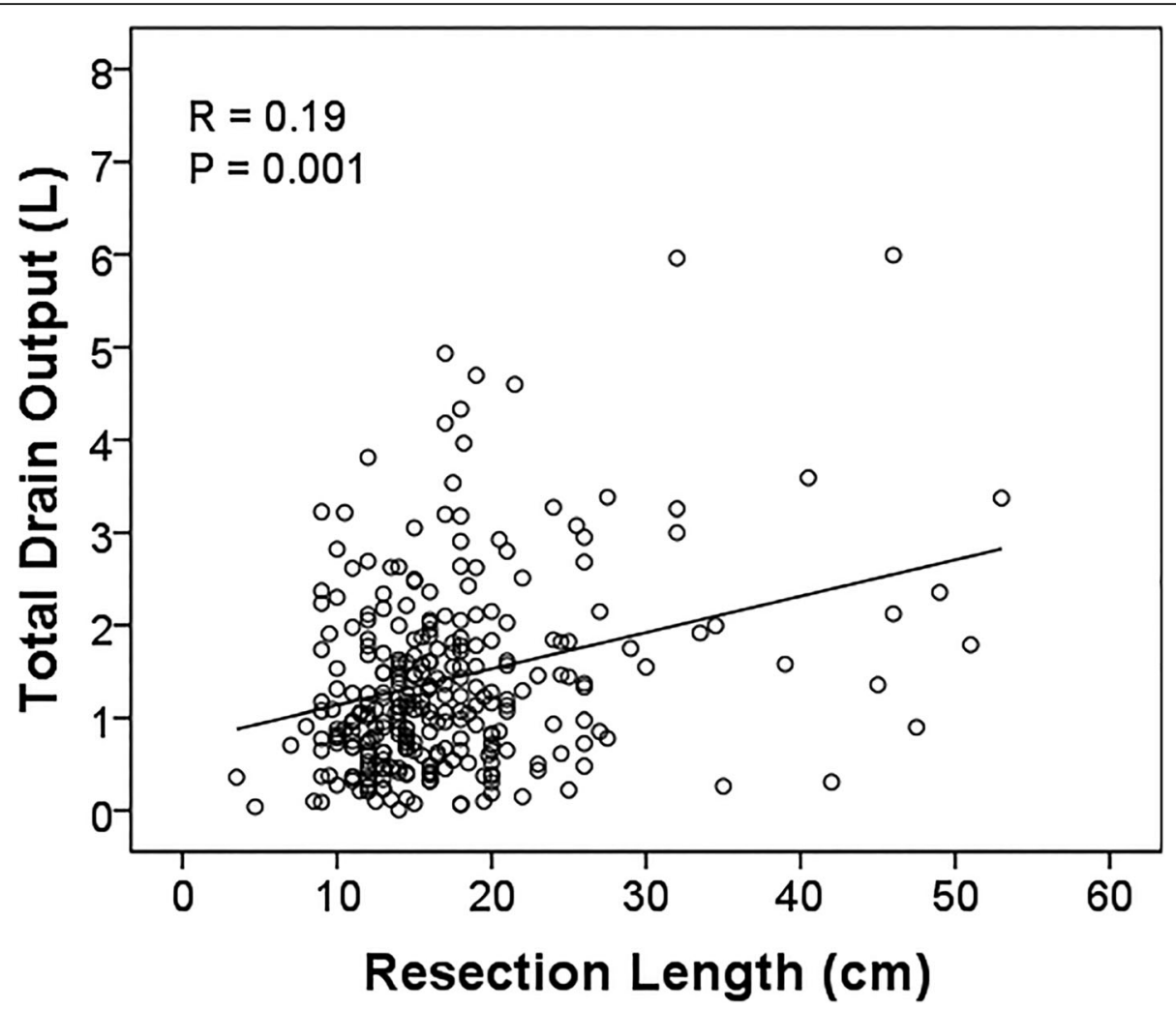

Fig. 3 Total drain output and resection length. Linear regression was performed to analyze the potential relationship between total drain output and resection length. A scatterplot with best-fit line is shown for total drain output ( $L$, liters) and resection length (Pearson's correlation coefficient $R=0.19, p=0.001)$

additional day of having a surgical drain increases the risk of wound infection by $42 \%$ for hip arthroplasty and $29 \%$ for knee arthroplasty [13]. It has also been shown that the degree of bacteriological contamination in drainage tubes increases after 3 days [24]. On the other hand, surgeons may fear removing a drain too early could lead to a large hematoma, which might also be a risk factor for infection [25].

A practical question is when to remove the drain. Although many surgeons wait until the rate of drainage diminishes to $30 \mathrm{~mL} /$ day, there is no published data to justify this practice. In our study, the mean rate of output at the time of drain removal was $72 \mathrm{~mL} /$ day, and there was no statistical difference in infected and uninfected cases. Furthermore, using the median value of 60 $\mathrm{mL} /$ day, there was no difference in infection rate for patients below or above the median. This was also true for a cut-off value of $30 \mathrm{~mL} /$ day. Our data suggests that one does not necessarily need to wait until the drainage reaches $30 \mathrm{~mL} /$ day to remove the drain. In fact, waiting excessively long for the drain output to reach this level could be detrimental, and our univariate analysis shows an association between duration of drains and risk of infection, consistent with data from conventional arthroplasty $[13,23]$. Some surgeons have advocated using no surgical drains at all, since data from randomized controlled trials for conventional arthroplasty do not support the routine use of closed suction drains $[25,26]$. Whether this concept can be applied to oncologic cases that involve extensive dissection remains to be determined.

High volume of drain output has been reported to be an adverse finding for infection risk [13]. In our study, it was a significant factor in univariate but not multivariate analysis. There are several potential reasons for this. The sample size may have been inadequate to establish high drain output as an independent variable. In addition, high drain output may have been dependent upon other variables. In our analysis, total drain output correlated with a number of factors, the most significant being duration of the surgical drains $(R=0.79)$. Total drain output also had a significant correlation with multiple drains, but the degree of correlation was weak $(R=0.19)$. A variety of other factors could also contribute to the total drain output including coagulopathy, hemostasis at the time of closure, wound closure technique, nutritional status, and anti-coagulant medications, especially for prophylaxis against venous thromboembolism [13]. We did not attempt to analyze the effect of these factors on drainage in this study. 
Table 3 Univariate analysis of factors for periprosthetic infection

\begin{tabular}{|c|c|c|c|c|}
\hline Variable & Group or measure & $\begin{array}{l}\text { Non-infected } \\
(n=264)\end{array}$ & $\begin{array}{l}\text { Infected } \\
(n=31)\end{array}$ & $P$ value \\
\hline Age (years) & Mean & 42 & 35 & $0.11^{\mathrm{a}}$ \\
\hline Resection length $(\mathrm{cm})$ & Mean & 17 & 20 & $0.05^{a}$ \\
\hline \multirow[t]{2}{*}{ Gender } & Male & 135 & 25 & $0.002^{b}$ \\
\hline & Female & 129 & 6 & \\
\hline \multirow[t]{3}{*}{ Pathology } & Benign & 14 & 0 & $0.38^{b}$ \\
\hline & Sarcoma & 170 & 25 & $0.08^{b}$ \\
\hline & Metastasis & 80 & 6 & $0.30^{b}$ \\
\hline \multirow[t]{4}{*}{ Site } & Proximal femur & 85 & 12 & $0.73^{b}$ \\
\hline & Distal femur & 118 & 13 & \\
\hline & Proximal tibia & 50 & 4 & \\
\hline & Total femur & 11 & 2 & \\
\hline \multirow[t]{4}{*}{ Surgeon } & A & 92 & 11 & $0.42^{b}$ \\
\hline & B & 66 & 8 & \\
\hline & C & 30 & 3 & \\
\hline & Others & 76 & 9 & \\
\hline \multirow[t]{2}{*}{ Preoperative chemotherapy } & Yes & 160 & 26 & $0.001^{b}$ \\
\hline & No & 104 & 5 & \\
\hline \multirow[t]{2}{*}{ Postoperative chemotherapy } & Yes & 85 & 22 & $0.01^{b}$ \\
\hline & No & 170 & 4 & \\
\hline \multirow[t]{2}{*}{ Both pre- and postoperative chemotherapy } & Yes & 127 & 25 & $0.001^{b}$ \\
\hline & No & 137 & 6 & \\
\hline \multirow[t]{2}{*}{ Any chemotherapy } & Yes & 180 & 26 & $0.10^{b}$ \\
\hline & No & 84 & 5 & \\
\hline \multirow[t]{2}{*}{ Preoperative radiotherapy } & Yes & 35 & 3 & $0.78^{b}$ \\
\hline & No & 229 & 28 & \\
\hline \multirow[t]{2}{*}{ Postoperative radiotherapy } & Yes & 24 & 2 & $1.00^{b}$ \\
\hline & No & 240 & 29 & \\
\hline \multirow[t]{2}{*}{ Number of drains } & 1 & 178 & 16 & $0.06^{b}$ \\
\hline & $\geq 2$ & 86 & 15 & \\
\hline Duration of drains (days) & Mean & 8.1 & 10.0 & $0.04^{\mathrm{a}}$ \\
\hline Total drainage $(\mathrm{mL})$ & Mean & 1,332 & 2,138 & $0.007^{\mathrm{a}}$ \\
\hline Rate of drainage (mL/day) & Mean & 167 & 198 & $0.07^{a}$ \\
\hline Last drainage $^{c}(\mathrm{~mL} /$ day $)$ & Mean & 73 & 70 & $0.86^{a}$ \\
\hline \multirow[t]{2}{*}{ Last drainage $^{c}(\mathrm{~mL} /$ day) } & $\leq 30$ & 78 & 10 & $0.84^{b}$ \\
\hline & $>30$ & 186 & 21 & \\
\hline \multirow[t]{2}{*}{ Last drainage ${ }^{c}(\mathrm{~mL} /$ day $)$} & $\leq 60$ & 138 & 14 & $0.57^{b}$ \\
\hline & $>60$ & 126 & 17 & \\
\hline \multirow[t]{2}{*}{ Last drainage $^{c}(\mathrm{~mL} /$ day) } & $\leq 120$ & 214 & 27 & $0.62^{b}$ \\
\hline & $>120$ & 50 & 4 & \\
\hline Duration of surgery (hours) & Mean & 5.2 & 6.2 & $0.05^{a}$ \\
\hline \multirow[t]{2}{*}{ Re-dose antibiotics in surgery } & Yes & 64 & 14 & $0.03^{b}$ \\
\hline & No & 143 & 12 & \\
\hline Estimated blood loss (mL) & Mean & 759 & 1,176 & $0.09^{a}$ \\
\hline
\end{tabular}

\footnotetext{
${ }^{a}$ Student's $t$ test

bearson's chi-square test or Fisher's exact test

'Last day of drainage prior to drain removal
} 
Table 4 Multivariate Cox regression analysis for periprosthetic infection-factors in final equation

\begin{tabular}{llllll}
\hline Variable & $\mathbf{B}$ & $\mathbf{S E}$ & $\mathbf{H R}\left(\boldsymbol{e}^{\mathbf{B}}\right)$ & $\mathbf{9 5 \%} \mathbf{C l}$ & $\boldsymbol{P}$ value \\
\hline Male gender & 0.92 & 0.51 & 2.50 & $0.9-6.8$ & 0.08 \\
Chemotherapy (preoperative) & 1.19 & 0.55 & 3.29 & $1.1-9.6$ & 0.03 \\
Sarcoma & 1.42 & 0.55 & 4.13 & $1.4-12.2$ & 0.01
\end{tabular}

$B$ Beta coefficient; SE standard error; $H R$ hazard ratio; $C l$ confidence interval

Some surgeons believe that early infection is related to wound problems, while late infection is due to hematogenous spread [27]. It may be difficult to decide what time point should be the cut-off for early infections. Due to the possibility that seeding of an implant in the perioperative period could manifest in a delayed manner, particularly for indolent organisms, we chose to include all infections in our analysis. Indeed, at least 6 of the late infections in our series were due to organisms such as Propionibacterium acnes, which might be deemed indolent. In contrast, Staphylococcus aureus, particularly the more virulent methicillin-resistant type, clustered in the early infections with onset within 1 year of surgery.

The multivariate analysis indicated that sarcoma diagnosis and preoperative chemotherapy were independent predictive factors for infection. We had included both factors in the analysis since we could not determine a priori which would potentially be a stronger predictive factor. Furthermore, even though these two factors might seem similar, they are not equivalent, for some sarcoma patients, such as those with conventional chondrosarcoma, do not receive preoperative chemotherapy. What this finding might suggest is that more extensive resections, which would include bone and soft tissue, may play an important role in the development of infection. In contrast, resections of aggressive benign tumors, such as giant cell tumor of bone, usually do not require substantial soft tissue removal. This is also generally true for many metastatic carcinomas that are treated with resection and endoprosthetic replacement.

Limitations of this study include the retrospective nature of the analysis and the fact that management of drains was not determined by a prospective protocol. We chose to focus our study on aspects of drain management. There may be other factors important to infection, such as nutritional status of patients and comorbidities, so our list of risk factors should not be considered a complete, exhaustive list. The rate of infection may be an underestimate of the true rate since patients who are lost to follow-up may still be at risk for subsequent infection.

\section{Conclusions}

Our data does not support waiting until drainage reaches $30 \mathrm{~mL} /$ day before drain removal. There was no difference in infection rate for patients who had drain removal less than or greater than $30 \mathrm{~mL} /$ day. In this cohort, the mean drain output at the time of removal was $72 \mathrm{~mL} /$ day, and there was no apparent increase in risk at this level of output either. Sarcoma diagnosis and preoperative chemotherapy were independent factors for infection in multivariate analysis. Future work is needed to examine the predictive value of other variables in periprosthetic infection and whether some patients may be managed without drains altogether.

\section{Acknowledgements \\ Not applicable}

\section{Authors' contributions}

$J \mathrm{~L}, \mathrm{ZF}$, and PPL conceived and designed the study. JL, ZF, MEB, and PPL collected the data and generated the data files. $J, Z F$, and PPL analyzed the data. $J L, Z F, M E B$, and PPL wrote the paper. $J$, ZF, MEB, VOL, BSM, RLS, SJF, and JEB provided critical review of the study design, data analysis, and manuscript. The authors have read and approved the final manuscript.

\section{Funding}

This research did not receive any specific grant from funding agencies in the public, commercial, or not-for-profit sectors.

\section{Availability of data and materials}

The datasets used and/or analyzed during the current study are available from the corresponding author on reasonable request.

\section{Ethics approval and consent to participate}

The study was approved by the Institutional Review Board. Informed consent was deemed not applicable since the study is purely retrospective in nature, and therefore, written informed consent for participation was not obtained for adults or children under 16 years of age.

Consent for publication

Not applicable.

\section{Competing interests}

PPL has received publishing royalties from Springer-Nature unrelated to the current study.

\section{Author details}

${ }^{1}$ Present address: Department of Bone and Soft Tissue Tumor, Peking University Cancer Hospital and Institute, Beijing, China. ${ }^{2}$ Present address: Department of Orthopaedic Surgery and Rehabilitation Medicine, State University of New York, Downstate Health Sciences University, Brooklyn, NY, USA. ${ }^{3}$ Department of Orthopedic Oncology, MD Anderson Cancer Center, Houston, TX, USA.

Received: 17 February 2020 Accepted: 1 February 2021

Published online: 15 February 2021

\section{References}

1. Racano A, Pazionis T, Farrokhyar F, Deheshi B, Ghert M. High infection rate outcomes in long-bone tumor surgery with endoprosthetic reconstruction in adults: a systematic review. Clin Orthop Relat Res. 2013;471(6):2017-27.

2. Morris CD, Sepkowitz K, Fonshell C, Margetson N, Eagan J, Miransky J, Boland PJ, Healey J. Prospective identification of risk factors for wound infection after lower extremity oncologic surgery. Ann Surg Oncol. 2003; 10(7):778-82

3. Jeys LM, Grimer RJ, Carter SR, Tillman RM. Periprosthetic infection in patients treated for an orthopaedic oncological condition. J Bone Joint Surg Am. 2005;87(4):842-9. 
4. Illingworth KD, Mihalko WM, Parvizi J, Sculco T, McArthur B, el Bitar Y, Saleh $\mathrm{KJ}$. How to minimize infection and thereby maximize patient outcomes in total joint arthroplasty: a multicenter approach: AAOS exhibit selection. J Bone Joint Surg Am. 2013;95(8):e50.

5. Marchant MH Jr, Viens NA, Cook C, Vail TP, Bolognesi MP. The impact of glycemic control and diabetes mellitus on perioperative outcomes after total joint arthroplasty. J Bone Joint Surg Am. 2009;91(7):1621-9.

6. Hernandez-Vaquero D, Fernandez-Fairen M, Torres A, Menzie AM, Fernandez-Carreira JM, Murcia-Mazon A, Guerado E, Merzthal L. Treatment of periprosthetic infections: an economic analysis. ScientificWorld J. 2013; 2013:821650.

7. Whitehouse JD, Friedman ND, Kirkland KB, Richardson WJ, Sexton DJ. The impact of surgical-site infections following orthopedic surgery at a community hospital and a university hospital: adverse quality of life, excess length of stay, and extra cost. Infect Control Hosp Epidemiol. 2002;23(4): 183-9.

8. Zajonz D, Zieme A, Prietzel T, Moche M, Tiepoldt S, Roth A, Josten C, von Salis-Soglio GF, Heyde CE, Ghanem M. Periprosthetic joint infections in modular endoprostheses of the lower extremities: a retrospective observational study in 101 patients. Patient Saf Surg. 2016;10:6.

9. Tunn P-U. The long-term risks of infection and amputation with limb salvage surgery using endoprostheses. Recent Results Cancer Res. 2009; 179(1):75-84.

10. Laitinen M, Parry M, Ratasvuori M, Wedin R, Albergo Jl, Jeys L, Abudu A, Carter S, Gaston L, Tillman R, et al. Survival and complications of skeletal reconstructions after surgical treatment of bony metastatic renal cell carcinoma. Eur J Surg Oncol. 2015;41(7):886-92.

11. Morii T, Morioka H, Ueda T, Araki N, Hashimoto N, Kawai A, Mochizuki K, Ichimura S. Deep infection in tumor endoprosthesis around the knee: a multi-institutional study by the Japanese musculoskeletal oncology group. BMC Musculoskelet Disord. 2013;14:51.

12. Kawai A, Lin PP, Boland PJ, Athanasian EA, Healey JH. Relationship between magnitude of resection, complication, and prosthetic survival after prosthetic knee reconstructions for distal femoral tumors. J Surg Oncol. 1999;70(2):109-15.

13. Patel VP, Walsh M, Sehgal B, Preston C, DeWal H, Di Cesare PE. Factors associated with prolonged wound drainage after primary total hip and knee arthroplasty. J Bone Joint Surg Am. 2007;89(1):33-8.

14. Jaberi FM, Parvizi J, Haytmanek CT, Joshi A, Purtill J. Procrastination of wound drainage and malnutrition affect the outcome of joint arthroplasty. Clin Orthop Relat Res. 2008;466(6):1368-71.

15. Jaberi MF, Eslampour A, Haytmanek CT, Parvizi J, Ghanem E, Purtill J. Persistent surgical wound drainage after total hip and knee arthroplasty-risk factors and final outcome. J Bone Joint Surg Br. 2009;91(12 Supp II):298.

16. Hemmat SM, Wang SJ, Ryan WR. Neck dissection technique commonality and variance: a survey on neck dissection technique preferences among head and neck oncologic surgeons in the American Head and Neck Society. Int Arch Otorhinolaryngol. 2017;21(1):8-16.

17. Tamplen ML, Tamplen J, Shuman E, Heaton CM, George JR, Wang SJ, Ryan WR. Comparison of output volume thresholds for drain removal after selective lateral neck dissection: a randomized clinical trial. JAMA Otolaryngol Head Neck Surg. 2017;143(12):1195-9.

18. Parvizi J, Ghanem E, Sharkey P, Aggarwal A, Burnett RS, Barrack RL. Diagnosis of infected total knee: findings of a multicenter database. Clin Orthop Relat Res. 2008;466(11):2628-33.

19. Henderson ER, Groundland JS, Pala E, Dennis JA, Wooten R, Cheong D, Windhager R, Kotz Rl, Mercuri M, Funovics PT, et al. Failure mode classification for tumor endoprostheses: retrospective review of five institutions and a literature review. J Bone Joint Surg Am. 2011;93(5):418-29.

20. Aponte-Tinao LA, Ayerza MA, Muscolo DL, Farfalli GL. What are the risk factors and management options for infection after reconstruction with massive bone allografts? Clin Orthop Relat Res. 2016;474(3):669-73.

21. Jamsen $E$, Huhtala H, Puolakka T, Moilanen T. Risk factors for infection after knee arthroplasty. A register-based analysis of 43,149 cases. J Bone Joint Surg Am. 2009;91(1):38-47.

22. Namba RS, Inacio MC, Paxton EW. Risk factors associated with deep surgical site infections after primary total knee arthroplasty: an analysis of 56,216 knees. J Bone Joint Surg Am. 2013;95(9):775-82.

23. Saleh K, Olson M, Resig S, Bershadsky B, Kuskowski M, Gioe T, Robinson H, Schmidt R, McElfresh E. Predictors of wound infection in hip and knee joint replacement: results from a 20 year surveillance program. J Orthop Res. 2002;20(3):506-15.

24. Schmitt S, Weyand F. Correlation between postoperative duration of Redon drainage and wound healing: a study of 150 patients with total endoprosthetic hip replacement. Unfallchirurgie. 1997;23(5):205-9.

25. Parker MJ, Roberts CP, Hay D. Closed suction drainage for hip and knee arthroplasty. A meta-analysis. J Bone Joint Surg Am. 2004;86(6):1146-52.

26. Zhang QD, Guo WS, Zhang Q, Liu ZH, Cheng LM, Li ZR. Comparison between closed suction drainage and nondrainage in total knee arthroplasty: a meta-analysis. J Arthroplasty. 2011;26(8):1265-72.

27. Young H, Hirsh J, Hammerberg EM, Price CS. Dental disease and periprosthetic joint infection. J Bone Joint Surg Am. 2014;96(2):162-8.

\section{Publisher's Note}

Springer Nature remains neutral with regard to jurisdictional claims in published maps and institutional affiliations.
Ready to submit your research? Choose BMC and benefit from:

- fast, convenient online submission

- thorough peer review by experienced researchers in your field

- rapid publication on acceptance

- support for research data, including large and complex data types

- gold Open Access which fosters wider collaboration and increased citations

- maximum visibility for your research: over $100 \mathrm{M}$ website views per year

At $\mathrm{BMC}$, research is always in progress.

Learn more biomedcentral.com/submissions 